\title{
PENGEMBANGAN SISTEM PAKAR UNTUK MENGIDENTIFIKASI PERMASALAHAN LAYANAN JARINGAN INTERNET
}

\author{
Junaidy B. Sanger ${ }^{1}$, Fitri Insani ${ }^{2}$, Priyo P. Nugroho ${ }^{3}$ \\ Program Studi Teknik Informatika ${ }^{12}$ \\ Universitas Katolik De La Salle Manado ${ }^{1}$ \\ Universitas Islam Negeri Sultan Syarif Kasim Riau \\ Institut Pertanian Bogor ${ }^{3}$ \\ e-mail: jsanger@unikadelasalle.ac.id ${ }^{1}$, fitri.insani@uin-suska.ac.id ${ }^{2}$, priyobanget@gmail.com ${ }^{3}$
}

\begin{abstract}
This study focuses on the development of an expert system that contains the knowledge of an expert who is believed to be the truth so as to help network officers to identify and address the disruption of Internet network services quickly and accurately. The stages of the expert system developed are the identification of internet network problems, the search for sources of knowledge, the acquisition of knowledge with 10 interruptions and 21 causes of interference from experts, knowledge representation, inference engine development using j48 classification algorithms with the help of weka applications, and system implementation. The system has been successfully created with an inference engine accuracy of $91.8 \%$.
\end{abstract}

Keywords: $\quad$ Expert System, Internet Network Problems, J48, Weka

\section{A. PENDAHULUAN}

Internet merupakan kebutuhan yang memiliki peranan sangat penting saat ini untuk digunakan oleh berbagai pihak. Salah satunya adalah pihak yang bergerak di dalam dunia pendidikan yaitu perguruan tinggi. Di Indonesia sendiri hampir semua perguruan tinggi baik negeri maupun swasta telah memanfaatkan internet untuk mendukung dan melancarkan sebagian besar aktifitas akademik maupun nonakademiknya.

Institut Pertanian Bogor (IPB) adalah salah satu perguruan tinggi di Indonesia yang telah memanfaatkan internet untuk mendukung segala aktifitasnya. Beberapa pemanfaatan layanan internet untuk aktifitas yang ada di IPB antara lain layanan untuk informasi penerimaan mahasiswa baru, penentuan pengisian rencana studi, repository online, perpustakaan, sistem kepegawaian, blog, payroll, dan sebagainya. Besarnya pemanfaatan dan pengaruh layanan internet bagi civitas akademika IPB semakin mendorong IPB untuk selalu dapat meningkatkan kualitas layanan internet baik dari segi infrastruktur jaringan, manajemen data maupun pengembangan aplikasi.

Sebuah sistem jaringan yang kompleks seperti yang terdapat di institusi pendidikan akan melibatkan begitu banyak komponen di dalamnya. Untuk mengatur agar seluruh sistem berjalan dengan baik diperlukan petugas jaringan yang mampu mengatasi permasalahan yang sering muncul. Petugas jaringan sangat penting kedudukannya dalam hal pemeliharaan (maintenance) jaringan internet. Petugaspetugas tersebut harus dapat memahami dan menguasai karakteristik jaringan internet dan mampu memperbaiki segala kerusakan yang terjadi.

Salah satu permasalahan yang sering dialami oleh pengguna layanan internet di IPB adalah gangguan layanan jaringan internet seperti akses internet yang tiba- tiba 
putus sama sekali (disconnect). Frekuensi gangguan layanan jaringan internet ini cukup sering, bahkan terjadi hampir setiap minggu. Faktor penyebabnyapun sangat beragam seperti masalah infrastruktur jaringan di setiap sub jaringan (fakultas, departemen, dan pusat penelitian), masalah server, firewall, proxy, maupun masalah provider.

Permasalahan pada jaringan internet IPB biasanya dapat segera diatasi oleh petugas jaringan yang berpengalaman sehingga penyebab dari gangguan tersebut dapat segera diketahui. Akan tetapi, jumlah petugas jaringan berpengalaman yang sangat menguasai dan memahami permasalahan internet IPB sangat terbatas jumlahnya.

Salah satu solusi dari permasalahan diatas adalah dengan membangun sebuah sistem pakar untuk mengidentifikasi dan mengatasi gangguan layanan jaringan internet di Institut Pertanian Bogor (IPB) dengan menggunakan metode Decision Tree berbasis web. Diharapkan sistem ini dapat membantu petugas jaringan dalam menentukan penyebab terjadinya diskoneksi internet.

Beberapa penelitian terkait yang pernah dilakukan sebelumnya, Morales et all, membangun sistem pakar berbasis web yang bertujuan untuk membantu administrator jaringan dalam masalahmasalah jaringan sehari-hari, yang di beri nama NeXPert. Sistem ini dibangun berbasis web agar dapat digunakan oleh banyak orang secara bersama-sama khususnya bagi administrator sistem yang kurang berpengalaman. Elisitasi pengetahuan bersumber dari artikel, buku serta wawancara dengan ahli jaringan komputer, dimana ahli berasal dari University of Puerto rico, departemen elektronika/komputer dan departemen computer centre. Sistem ini merupakan Rule based expert system dengan menggunakan representasi binary decision tree karena domain permasalahan mengikuti struktur hierarki. Terdiri atas node keputusan dan node jawaban. Proses inferensi dimulai dengan menetapkan lokasi inisial, yang biasanya adalah root node, dan mengikuti transisi ya/tidak hingga sampai ke node jawaban. dibangun dengan menggunakan tools seperti Java Expert System Shell (JESS) untuk integrasi basis pengetahuan serta CLIPS sebagai mesin inferensinya. Hasilnya merupakan advice (nasihat) berdasakan diagnosa dari permasalahan jaringan komunikasi. Penelitian lainnya juga, Lindqvist \& Porras (1999), mengembangkan perangkat pengembangan sistem pakar yang disebut Production-Based Expert System Toolset (P-BEST) yaitu berupa intrusion detection system components, yaitu untuk mendeteksi kesalahan penggunaan dan gangguan jaringan komputer yang dapat diintegrasikan dengan komponen lainnya. Penelitian ini juga merupakan rule based expert system yang menggunakan production rule sebagai representasi dan forward chainning dalam proses inferensinya.

Penelitian ini berfokus pada pembuatan dan pengembangan sebuah sistem pakar yang berisi pengetahuan dari seorang pakar yang diyakini kebenarannya sehingga dapat membantu petugas jaringan untuk mengidentifikasi dan mengatasi gangguan layanan jaringan internet dengan cepat dan tepat.

\section{B. TINJAUAN PUSTAKA}

Sistem Pakar 
Menurut Dewi (2003), secara garis besar, banyak manfaat yang dapat diambil dengan adanya sistem pakar, antara lain:

1) Memungkinkan orang awam bisa mengerjakan pekerjaan para ahli.

2) Bisa melakukan proses secara berulang dengan automatis.

3) Menyimpan pengetahuan dengan keahlian para pakar.

4) Meningkatkan output dan produktivitas.

5) Meningkatkan kualitas.

6) Mampu mengambil dan melestarikan keahlian para pakar (terutama yang termasuk keahlian langka).

7) Mampu beroperasi dalam lingkungan yang berbahaya.

8) Memiliki kemampuan untuk mengakses pengetahuan.

9) Memiliki reliabilitas.

10) Meningkatkan kapabilitas sistem komputer.

11) Memiliki kemampuan untuk bekerja dengan informasi yang tidak lengkap dan mengandung ketidakpastian.

12) Sebagai media pelengkap dalam pelatihan.

13) Meningkatkan kapabilitas dalan penyelesaian masalah.

14) Menghemat waktu dalam pengambilan keputusan

Di samping memiliki beberapa kelebihan, sistem pakar juga memiliki kelemahan, antara lain sebagai berikut:

1) Biaya yang dibutuhkan untuk membuat dan memeliharanya sangat mahal.

2) Sulit dikembangkan, hal ini berkaitan dengan ketersediaan pakar di bidangnya.

3) Sistem pakar ini tidak $100 \%$ bernilai benar.
Konsep dasar sistem pakar meliputi enam hal berikut:

1) Kepakaran (Expertise)

2) Pakar (Expert)

3) Pemindahan Kepakaran (Transferring Expertise)

4) Inferensi (Inferencing)

5) Aturan-aturan (Rule)

6) Kemampuan Menjelaskan (Explanation Capability)

Ada dua bagian penting dari sistem pakar, yaitu lingkungan pengembangan (development environment) dan lingkungan konsultasi (consultation environment). Lingkungan pengembangan digunakan oleh pembuat sistem pakar untuk membangun komponen-komponennya dan memperkenalkan pengetahuan ke dalam knowledge base (basis pengetahuan). Lingkungan konsultasi digunakan oleh pengguna untuk berkonsultasi sehingga pengguna mendapatkan pengetahuan dan nasihat dari sistem pakar layaknya berkonsultasi dengan seorang pakar. Gambar 1 menunjukkan komponenkomponen yang dimaksud.

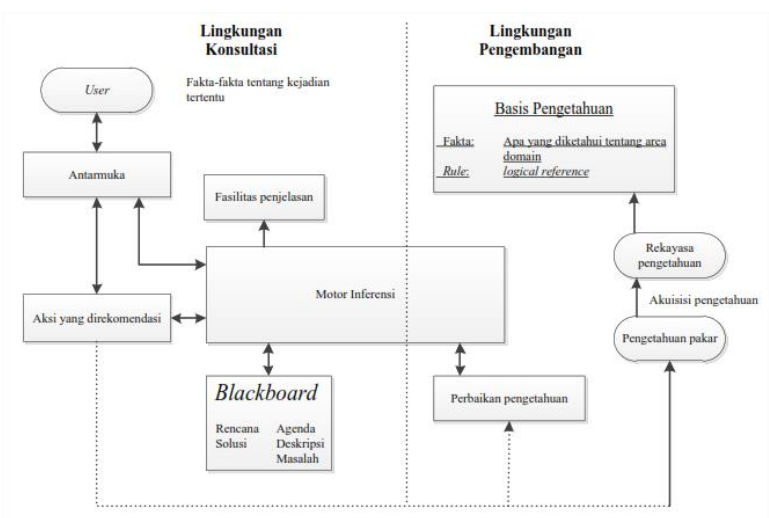

Gambar 1. Komponen-komponen yang penting dalam sistem pakar

Keterangan:

1. Akuisisi Pengetahuan

Subsistem ini digunakan untuk memasukan pengetahuan dari seorang 
pakar dengan cara merekayasa pengetahuan agar bisa diproses oleh komputer dan menaruhnya ke dalam basis pengetahuan dengan format tertentu (dalam bentuk representasi pengetahuan). Sumber-sumber pengetahuan bisa diperoleh dari pakar, buku, dokumen multimedia, basis data, laporan riset khusus, dan informasi yang terdapat di web.

2. Basis Pengetahuan (Knowledge Base) Basis pengetahuan mengandung pengetahuan yang diperlukan untuk memahami, memformulasikan, dan menyelesaikan masalah. Basis pengetahuan terdiri dari dua elemen dasar, yaitu:

a) Fakta, misalnya situasi, kondisi, atau permasalahan yang ada.

b) Rule (Aturan), untuk mengarahkan penggunaan pengetahuan dalam memecahkan masalah.

3. Mesin Inferensi (Inference Engine) Mesin inferensi adalah sebuah program yang berfungsi untuk memandu proses penalaran terhadap suatu kondisi berdasarkan pada basis pengetahuan yang ada, memanipulasi dan mengarahkan kaidah, model, dan fakta yang disimpan dalam basis pengetahuan untuk mencapai solusi atau kesimpulan. Dalam prosesnya, mesin inferensi menggunakan strategi pengendalian, yaitu strategi yang berfungsi sebagai panduan arah dalam melakukan proses penalaran. Ada tiga teknik pengendalian yang digunakan, yaitu forward chaining, backward chaining, dan gabungan dari kedua teknik tersebut.

4. Daerah Kerja (Blackboard)
Untuk merekam hasil sementara yang akan dijadikan sebagai keputusan dan untuk menjelaskan sebuah masalah yang sedang terjadi, sistem pakar membutuhkan blackboard, yaitu area pada memori yang berfungsi sebagai basis data.

5. Antarmuka Pengguna (User Interface)

Digunakan sebagai media komunikasi antara pengguna dan Sistem Pakar. Komunikasi ini paling bagus bila disajikan dalam bahasa alami (natural language) dan dilengkapi dengan grafik, menu, dan formulir elektronik. Pada bagian ini akan terjadi dialog antara Sistem Pakar dan pengguna.

6. Subsistem Penjelasan (Explanation Subsystem/ Justifier)

Berfungsi memberi penjelasan kepada pengguna, bagaimana suatu kesimpulan dapat diambil. Kemampuan seperti ini sangat penting bagi pengguna untuk mengetahui proses pemindahan keahlian pakar maupun dalam pemecahan masalah

7. Subsistem Penjelasan (Explanation Subsystem/ Justifier)

Kemampuan memperbaiki pengetahuan (knowledge refining system) dari seorang pakar diperlukan untuk menganalisis pengetahuan, belajar dari kesalahan masa lalu, kemudian memperbaiki pengetahuannya sehingga dapat dipakai pada masa mendatang. Kemampuan evaluasi diri seperti itu diperlukan oleh program agar dapat menganalisis alasan-alasan kesuksesan dan kegagalannya dalam mengambil kesimpulan. Dengan cara 
ini basis pengetahuan yang lebih baik dan penalaran yang lebih efektif akan dihasilkan.

\section{Pengguna (User)}

Pada umumnya pengguna sistem pakar bukanlah seorang pakar (nonexpert) yang membutuhkan solusi, saran, atau pelatihan (training) dari berbagai permasalahan yang ada.

\section{Decision Tree}

Decision tree adalah suatu metode yang digunakan untuk mengubah data menjadi pohon keputusan dan atura-aturan keputusan (rule) . Pada desain proses akan dijelaskan menggunakan decision tree yang berhubungan dengan tabel dan sering digunakan dalam analisis sistem (sistem non AI). Sebuah decision tree dapat dianggap sebagai suatu semantic network hierarchy yang diikat oleh serangkaian aturan (rule). Tree ini mirip dengan pohon keputusan yang digunakan pada teori keputusan. Tree dibentuk oleh simpul (node) yang mempresentasikan tujuan (goal) dan hubungan (link) yang dapat mempresentasikan keputusan (decision). Akar (root) dari pohon berada disebelah kiri dan daun (leaf) berada di sebelah kanan. Keuntungan utama dari decision tree yaitu tree dapat menyederhanakan proses akuisi pengetahuan (Hamdani, 2010).

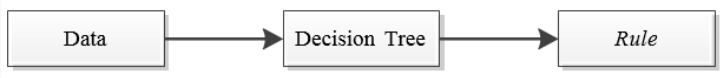

Gambar 2. Proses Akuisisi data menggunakan Decision Tree

Proses akuisisi data menggunakan Decision Tree adalah sebagai berikut:

1. Mengubah bentuk data menjadi model pohon (tree)

2. Mengubah model pohon menjadi rule

3. Menyederhanakan rule (pruning)

\section{Forward Chaining}

Forward chaining merupakan fakta untuk mendapatkan kesimpulan (conclusion) dari fakta tersebut (Giarratano dan Riley, 1994). Penalaran ini berdasarkan fakta yang ada (data driven), metode ini adalah kebalikan dari metode backward chaining, dimana metode ini dijalankan dengan mengumpulkan fakta- fakta yang ada untuk menarik kesimpulan. Dengan kata lain, prosesnya dimulai dari facts (faktafakta yang ada) melalui proses inference fact (penalaran fakta-fakta) menuju suatu goal (suatu tujuan). Metode ini bisa juga disebut menggunakan aturan IF-THEN dimana premise (IF) menuju conclusion (THEN) atau dapat juga dituliskan sebagai berikut THEN (conclusion).

\section{Jaringan Internet}

Internet (Inter-Networking) adalah sebutan untuk sekumpulan jaringan komputer yang menghubungkan situs akademik, pemerintahan, komersial, organisasi, maupun perorangan. Internet menyediakan akses untuk layanan telekomunikasi dan sumber daya informasi untuk jutaan pemakainya yang tersebar di seluruh dunia. Layanan internet meliputi komunikasi langsung (email, chat), diskusi (email, milis), sumber daya informasi yang terdistribusi (World Wide Web, Gopher), remote login dan lalu lintas file (Telnet, FTP), dan aneka layanan lainnya.

Jaringan yang membentuk internet bekerja berdasarkan suatu set protokol standar yang digunakan untuk menghubungkan jaringan komputer dan mengalamati lalu lintas dalam jaringan. Protokol ini mengatur format data yang diijinkan, penanganan kesalahan (error handling), lalu lintas pesan, dan standar komunikasi lainnya. Protokol standar pada internet dikenal sebagai TCP/IP (Transmission Control Protocol/Internet 
Protocol). Protokol ini memiliki kemampuan untuk bekerja diatas segala jenis komputer, tanpa terpengaruh oleh perbedaan perangkat keras maupun sistem operasi yang digunakan. Sebuah sistem komputer yang terhubung secara langsung ke jaringan memiliki nama domain dan alamat IP (Internet Protocol) dalam bentuk numerik dengan format tertentu sebagai pengenal. Internet juga memiliki gateway ke jaringan dan layanan yang berbasis protokol lainnya.

\section{METODE}

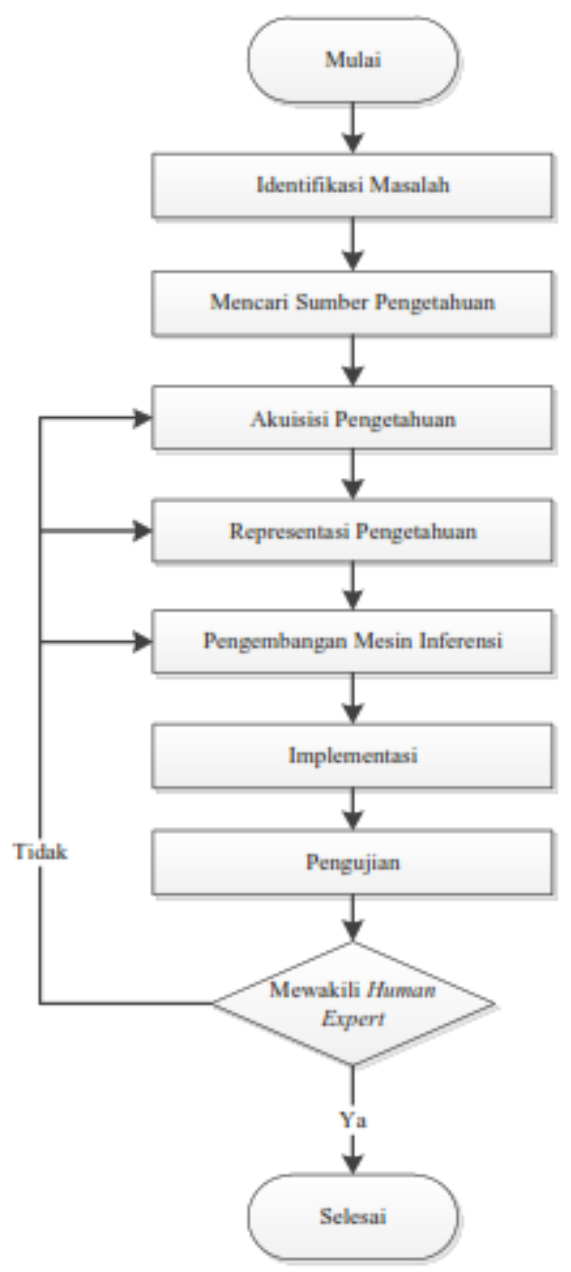

Gambar 3. Tahap pengembangan sistem pakar (Marimin, 2009)
Lokasi Penelitian di Institut Pertanian Bogor. Alat dan Bahan yang digunakan dalam pengembangan Sistem ini adalah sebagai berikut:

1. Notebook dengan spesifikasi ASUS UL80VT, Processor Core 2 duo 1.3 GHz, RAM 4GB DDR3

2. Sistem Operasi Microsoft Windows 8 Pro (32-bit)

3. Bahasa pemrograman PHP, DBMS MySQL, dan framework Code Igniter (CI)

4. Aplikasi Inferensi Weka 3.6.9

Adapun langkah-langkah penelitian yang dilakukan seperti pada Gambar 3.

\section{HASIL DAN PEMBAHASAN}

\section{Identifikasi Masalah}

Salah satu permasalahan yang sering dialami oleh pengguna layanan internet di IPB adalah gangguan layanan jaringan internet seperti akses internet yang tiba- tiba putus sama sekali (disconnect). Frekuensi gangguan layanan jaringan internet ini cukup sering, bahkan terjadi hampir setiap minggu. Faktor penyebabnyapun sangat beragam seperti masalah infrastruktur jaringan di setiap sub jaringan (fakultas, departemen, dan pusat penelitian), masalah server, firewall, proxy, maupun masalah provider. Permasalahan pada jaringan internet IPB biasanya dapat segera diatasi oleh petugas jaringan yang berpengalaman sehingga penyebab dari gangguan tersebut dapat segera diketahui. Akan tetapi, jumlah petugas jaringan berpengalaman yang sangat menguasai dan memahami permasalahan internet IPB sangat terbatas jumlahnya. Maka dari itu, untuk menyelesaikan permasalahan tersebut dengan membangun sebuah sistem pakar untuk mengidentifikasi dan mengatasi 
gangguan layanan jaringan internet di Institut Pertanian Bogor (IPB) dengan menggunakan metode decision tree berbasis web.

\section{Mencari Sumber Pengetahuan}

Sumber pengetahuan diperoleh dari pakar dan beberapa publikasi tentang penelitian yang terkait. Pakar yang dipilih adalah Bapak Hasan, administrator jaringan IPB yang sangat berpengalaman dibidangnya selama sekitar sepuluh tahun. Hasil dari sumber pengetahuan ini akan dijadikan sumber akuisisi pengetahuan dari sistem yang akan dibuat.

\section{Akuisisi Pengetahuan}

Akuisisi pengetahuan yang dilakukan dalam sistem ini menggunakan metode wawancara dengan pakar. Bentuk wawancara yang dilakukan adalah kombinasi unstructured interview dan structured interview. Unstructured interview digunakan pada awal pertemuan dengan pakar untuk mengambil pengetahuan secara umum. Setelah pengetahuan secara umum diketahui, detail pengetahuan diperoleh dengan structured interview. Berdasarkan hasil wawancara, diperoleh beberapa gangguan dan penyebab (gejala) terjadinya gangguan diskoneksi internet. Gangguan- gangguan tersebut adalah sebagai berikut:

1. Tidak ada masalah jaringan

2. Masalah Proxy

3. Masalah DNS Publik

4. Masalah LDAP

5. Masalah Load Balancer/Captive Portal

6. Kesalahan pengaturan pada client

7. Masalah Router/Switch

8. Masalah Firewall

9. Masalah ISP/Provider
10. Antara jaringan client dengan jaringan pusat terputus

Gejala-gejala penyebab gangguan adalah sebagai berikut:

1. Captive Portal dapat dibuka

2. Login Captive Portal OK

3. MySQL pada Load Balancer OK

4. IP Load Balancer OK

5. Port Lighttpd pada Load Balancer OK

6. $\quad$ Tracert ke Load Balancer terputus

7. Domain publik OK

8. Ping Server DNS Publik OK

9. Ping IP Publik OK

10. Ping Domain Lokal OK

11. NSLOOKUP untuk Captive Portal menghasilkan IP yang benar

12. Ping Server DNS Lokal OK

13. Ping IP Proxy OK

14. Port Squid pada Server Proxy OK

15. Ping Server LDAP OK

16. Koneksi jaringan pusat ke jaringan luar OK

17. Ping Gateway OK

18. Client mendapatkan alamat IP yang benar

19. Client melakukan setting IP secara manual

20. Client menggunakan WLAN

21. Sinyal Access Point ditemukan

\section{Representasi Pengetahuan}

Berdasarkan hasil wawancara yang telah dilakukan, terdapat beberapa gejala gangguan jaringan untuk menyimpulkan beberapa kemungkinan lokasi gangguan jaringan. Masing-masing penyebab (gejala) gangguan pada koneksi internet diberi A1 hingga A21, sedangkan gangguan diberi kode B1 hingga B10. Test Case juga dilakukan pada tahap ini. 


\section{Pengembangan Mesin Inferensi}

Berdasarkan test case, kemudian dilakukan pengolahan untuk mendapatkan decision tree pada Gambar 4 menggunakan algoritma klasifikasi J48 dengan bantuan aplikasi WEKA. Diperoleh akurasi sebesar $91.8 \%$.

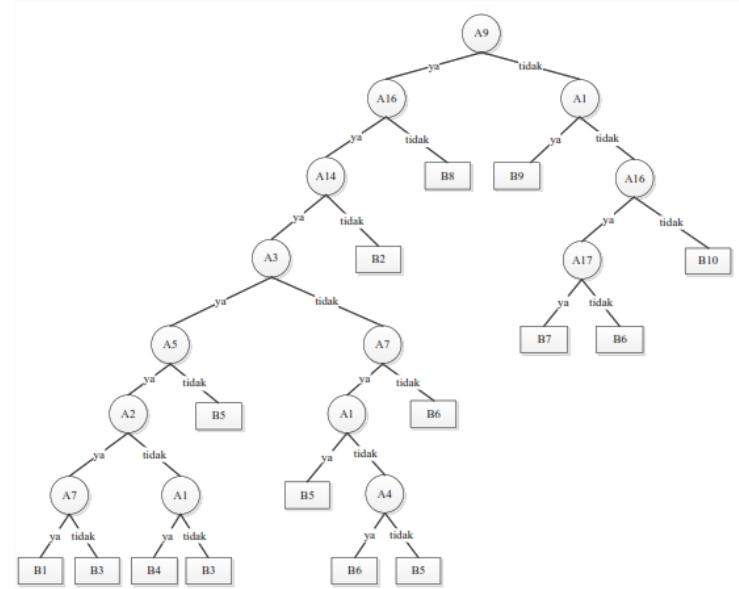

Gambar 4. Decision tree identifikasi gangguan diskoneksi internet

Adapun rule-rule yang diperoleh dapat dilihat pada Gambar 5.

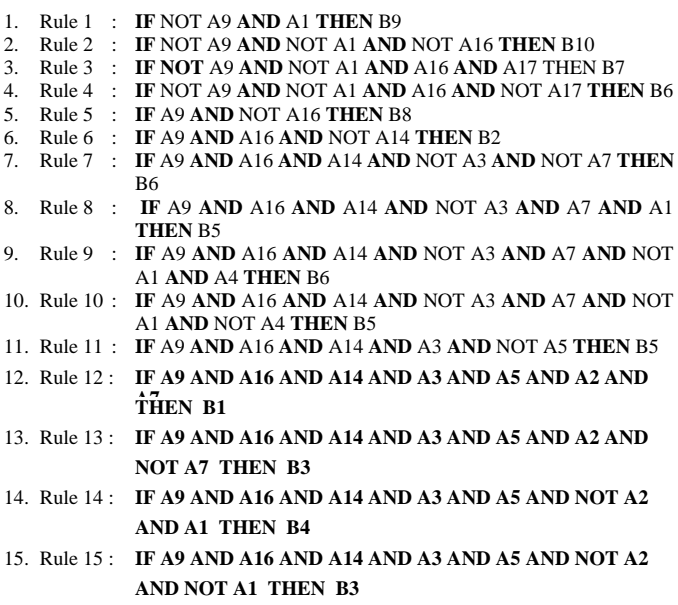

Gambar 5. Rule yang diperoleh dari test case

Gambar 6 adalah contoh kasus inferensi menggunakan decision tree berdasarkan rule yang ada (contoh berdasarkan rule 3 ):

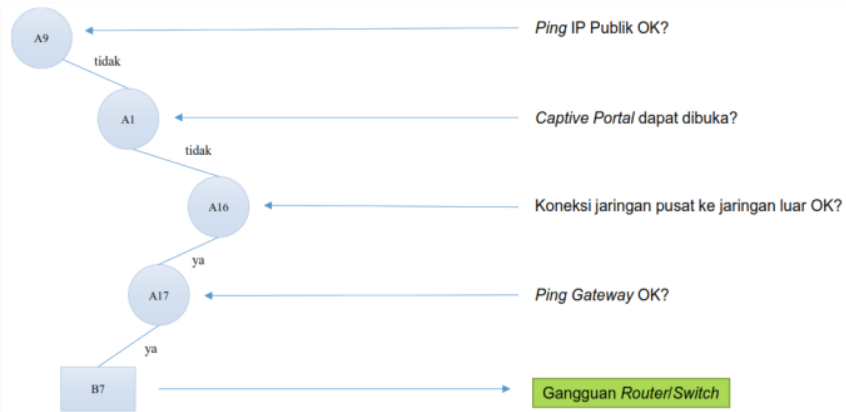

Gambar 6. Contoh kasus decision tree identifikasi gangguan diskoneksi internet

\section{Implementasi Sistem}

Berikut ini adalah hasil implementasi sistem pakar yang dikembangkan berbasis web dengan mengikuti kasus inferensi yang menggunakan decision tree seperti pada gambar 5 (contoh berdasarkan rule 3). Nama dari sistem pakar ini adalah SIPALAJANG dengan singkatan SIstem PAkar LAyanan JAriNGan. Untuk halaman utamanya seperti pada Gambar 7 dibawah ini. Contoh diagnosanya dapat dilihat pada Gambar 8, 9, 10, 11, dan Gambar 12.

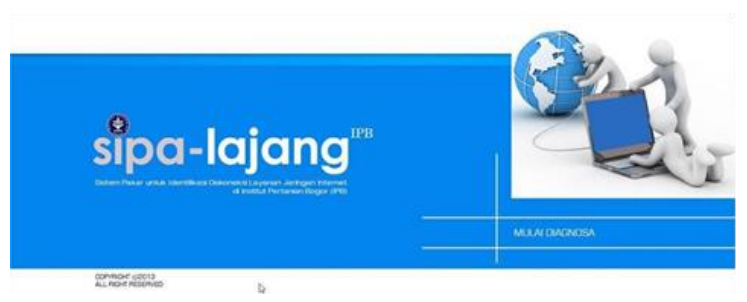

Gambar 7. Halaman utama Sipalajang

Pertanyaan 1 : Apakah ping IP publik $\mathrm{OK}$ ?

Jawaban : Tidak (contoh berdasarkan rule 3)

Pertanyaan 2 : Apakah Captive Portal dapat dibuka?

Jawaban : Tidak (contoh berdasarkan rule 3) 


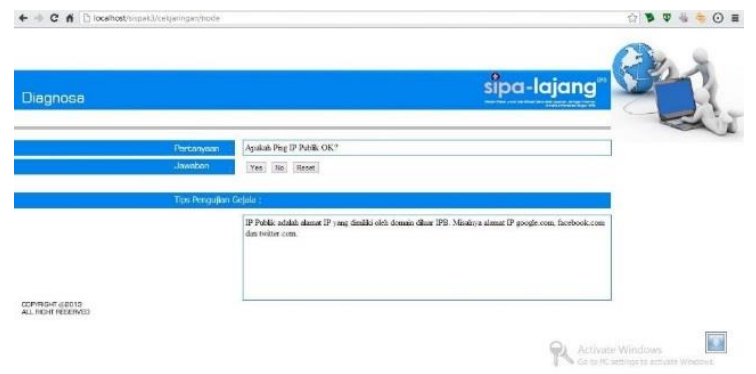

Gambar 8. Sipalajang pertanyaan diagnosa 1

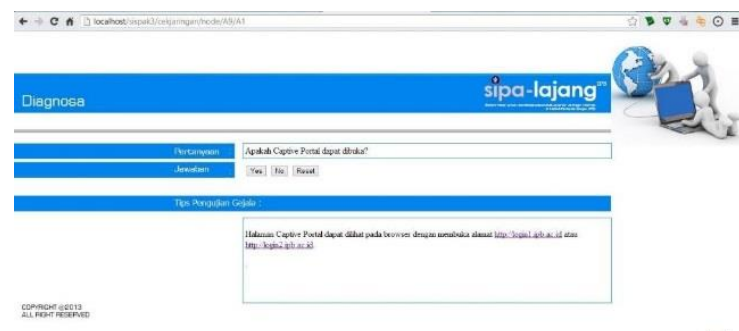

Gambar 9. Sipalajang pertanyaan diagnosa 2

Pertanyaan 3 : Apakah koneksi jaringan pusat ke jaringan luar $\mathrm{OK}$ ?

Jawaban : Ya (contoh berdasarkan rule 3)

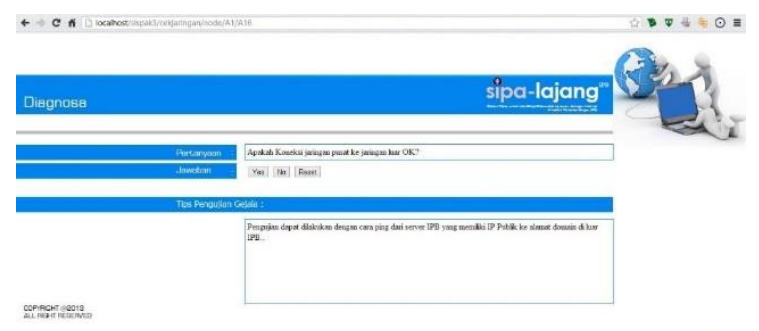

Gambar 10. Sipalajang pertanyaan diagnosa 3

Pertanyaan 4 : Apakah ping gateway OK?

Jawaban : Ya (contoh berdasarkan rule 3)

\section{Hasilnya : Router/Switch bermasalah}

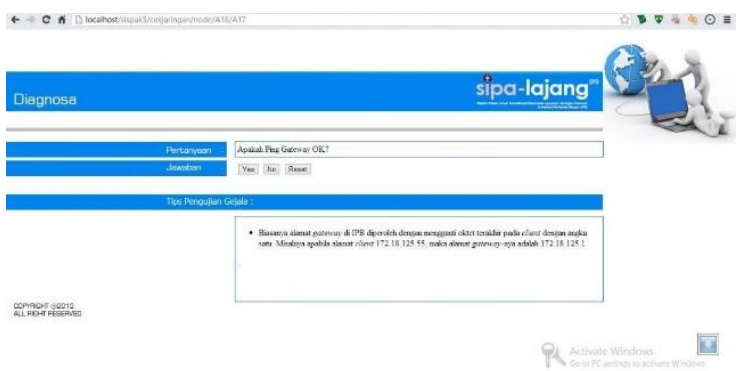

Gambar 11. Sipalajang pertanyaan diagnosa 4

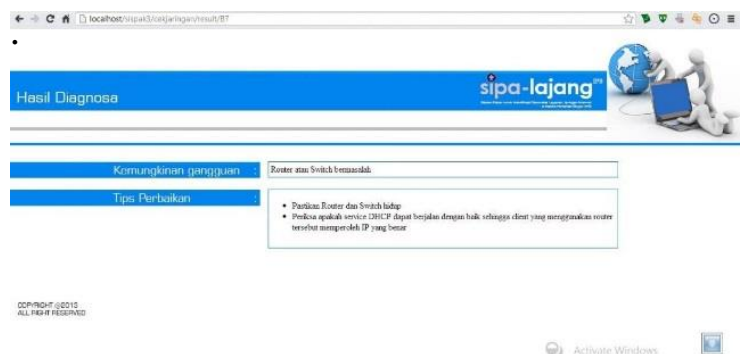

Gambar 12. Sipalajang hasil diagnosa

\section{E. KESIMPULAN DAN SARAN}

Dari hasil pembahasan, kesimpulan yang diperoleh dari penelitian ini adalah sistem pakar yang dibuat telah berhasil menemukan penyebab gangguan koneksi internet pada jaringan IPB. Akurasi yang diperoleh untuk mendapatkan decision tree sebesar 91.8\% dengan algoritma klasifikasi j48 menggunakan aplikasi Weka. Sistem pakar yang dihasilkan dalam penelitian ini tidaklah menyediakan solusi gangguan secara otomatis. Petugas sendiri yang harus menyelesaikan gangguan tersebut. Oleh karena itu, dalam penelitian selanjutnya dapat dikembangkan sebuah sistem pakar yang bekerja secara otomatis sehingga solusi dari gangguan dapat dilakukan sendiri oleh sistem pakar.

\section{F. DAFTAR PUSTAKA}

Cesar, C., Souza, C. 1998. An expert system for Pro-active computer network management. 
Dewi, K. 2003. Artificial Intelligence Teknik dan Aplikasinya. Graha Ilmu.

Giarratano J, Riley G. 1994. Expert Systems: Principles and Programming Second Edition. Boston: PWS Publishing Company.

Hamdani, 2010. Sistem Pakar Untuk Diagnosa Penyakit Mata Pada Manusia. Jurnal Informatika Mulawarman, 5(2).

Marimin. 2009. Teori dan Aplikasi Sistem Pakar dalam Teknologi Manajerial. Bogor: IPB Press.

Morales, A., Creus, A., Carvaja, PA. www-based Expert System Advisor for the Diagnostic of Network Communication Problems.

Naser, A., Zaiter, A. 2008. An Expert System For Diagnosing Eye Disease Using Clips. Journal of Theoretical and Applied Information Technology.

Setiawan, A. 2009. Sistem Pakar Untuk Mendiagnosa Penyakit Telinga Hidung Tenggorokan Pada Manusia. Jurnal Telkomnika. 7(3).

Sutojo, T., Mulyanto, E., Suhartono, V. 2011. Kecerdasan Buatan. Yogyakarta: Penerbit ANDI. 